\title{
Clinical characteristics of COVID-19 and establishment of a disease risk prediction model
}

\section{Tao Fan}

Wuhan University Renmin Hospital

\section{Bo Hao}

Wuhan University Renmin Hospital

\section{Shuo Yang}

Wuhan University Renmin Hospital

\section{Bo Shen}

Wuhan University Renmin Hospital

\section{Zhixin Huang}

Wuhan University Renmin Hospital

\section{Zilong Lu}

Wuhan University Renmin Hospital

\section{Rui Xiong}

Wuhan University Renmin Hospital

\section{Xiaokang Shen}

Wuhan University Renmin Hospital

\section{Wenyang Jiang}

Wuhan University Renmin Hospital

\section{Lin Zhang}

Wuhan University Renmin Hospital

\section{Donghang Li}

Wuhan University Renmin Hospital

\section{Ruyuan He}

Wuhan University Renmin Hospital

\section{Heng Meng}

Wuhan University Renmin Hospital

Weichen Lin

Wuhan University Renmin Hospital

\section{Haojie Feng}

Wuhan University Renmin Hospital

Qing Geng ( $\sim$ gengqingwhu@whu.edu.cn )

Wuhan University Renmin Hospital 
Research

Keywords: COVID-19, risk factors, prediction model

Posted Date: April 9th, 2020

DOI: https://doi.org/10.21203/rs.3.rs-21303/v1

License: (c) (i) This work is licensed under a Creative Commons Attribution 4.0 International License. Read Full License 


\section{Abstract}

Background: COVID-19 is spreading worldwide. No specific medicine has been used for the treatment of coronavirus infections. The aim of this study is to establish a new risk predictive model to screen potential critical patients for early intervention.

Methods: In this study, Clinical characteristics were collected and analyzed from 317 confirmed cases of COVID-19. A total of 175 of the 317 cases with detailed examination results were included to establish models for predicting the risk of disease progression. Major independent risk factors were incorporated into MuLBSTA model to establish new models for predicting critical risk. We further tracked 25 mild or moderate patients with COVID-19 to research dynamic changes of the major independent risk factors in COVID-19 progression.

Results: The average age of all of the 317 patients was 47.76 (SD 17.22). A total of 48 (15.14\%) were diagnosed with mild disease with a median age of $34(39.29 \pm 13.04), 116(36.59 \%)$ were diagnosed with moderate disease with a median age of $34(38.78 \pm 12.32), 38(11.99 \%)$ were diagnosed as severe with a median age of 56(58.24 \pm 15.12$)$, and $115(36.28)$ were diagnosed as critical with a median age of 59(56.89+17.09). The most common symptom at onset of illness were fever(211[66.56\%] patients). Age $>50, C K>64, C D 4 \leq 461$, and $C D 8 \leq 241$ were predicted to be major independent risk factors that could promote COVID-19 progression. Compared with the MuLBSTA model, the predictive ability of the CD4CD8-MuLBSTA model and the CD4-MuLBSTA model were improved by $11.87 \%$ and $11.79 \%$, respectively. In the prospective study, CK value began to show significant differences from day13. The average CD4 in Severe Group began to decline significantly on the fourth day, and the CD8 maintained a relatively low level in the Severe Group after day13.

Conclusions: Severe COVID-19 patients were significantly older than non-severe patients. Immune systems of severe COVID-19 patients were significantly suppressed, and advanced age(>50 years), low levels of CD4( $\leq 461)$ or CD8( $\leq 241)$ was important clinical manifestations of rapid deterioration. CK values in severe COVID-19 patients were significantly higher than in no severe patients. CD4 and CD8 were incorporated into the MuLBSTA to establish a new model, which is an ideal risk prediction model for COVID-19 patients.

\section{Background}

Coronavirus disease 2019(COVID-19) is a respiratory illness caused by a new virus(SARS-CoV-2, Severe Acute Respiratory Syndrome Coronavirus2), which was first reported in December 2019 in Wuhan, Hubei Province, China. ${ }^{1-5}$ Symptoms range from a mild cough to pneumonia, even with no symptoms. ${ }^{3,6}$ There is evidence that it spreads from person to person. ${ }^{7}$ Whole genome sequencing showed that COVID-19 is a beta coronavirus similar to human severe acute respiratory syndrome(SARS) and middle eastern respiratory syndrome(MERS). This new coronavirus claded from SARS and MERS requires enhanced surveillance and further investigation. ${ }^{8}$ Like other several coronaviruses, SARS-CoV-2 initially causes mild 
or moderate symptoms in most patients. Thus far, a smaller percentage of patients with SARS-CoV-2 have developed severe pneumonia. Although the average incubation period of SARS-CoV-2 in the human body is 14 days, some patients have progressed rapidly to respiratory failure once they had become infected. Early intervention in the risk factors that promote COVID-19 progression may inhibit the disease progression, which is very important to reduce the proportion of critically ill patients and improve the cure rate.

The aim of this study is to summarize the epidemiological and clinical characteristics of 317 patents with SARS-CoV-2 infections in the Renmin Hospital of Wuhan University from January 1 to January 31, 2020 to explore the independent risk factors for accurately assessing the severity incidence of SARS-CoV-2 infection. Then 25 mild or moderate patients with COVID-19 are tracked to study dynamic changes in the major independent risk factors from our predicting model in COVID-19 progression.

\section{Methods}

\section{Study design and patients}

For this retrospective single-center study, 317 patients were enrolled from January 1 to January 31, 2020 in the Renmin Hospital of Wuhan University. On February 6, 2020, 25 patients admitted to the Renmin Hospital of Wuhan University on February 5 and 6, 2020 were also recruited for dynamic tracking research. All of the patients in this study were diagnosed according to the WHO interim guidance. ${ }^{9}$ All of the patients with COVID-19 were diagnosed using a real-time PCR(RT-PCR) assay for SARS-CoV2(followed by "Pneumonitis diagnosis and treatment plan for SARS-CoV-2 infection(trial version5) "issued by the National Health Commission of the People's Republic of China(NHCPRC). The specific test methods steps were described previously. ${ }^{6}$

\section{Data sources and baseline design}

All of the 317 patient's clinical features, radiological characteristics, clinical laboratory, and outcome data were obtained from electronic medical records. Detailed patient information was collected, including past history, current medical history, laboratory findings, imaging data, treatment measures, symptoms, signs, and immune function test results. Follow-up was initiated from suspicion or confirmed diagnosis to the time when the patient became severe, to the time of discharge, or to January 31.

The 25 dynamic tracked cases were hospitalized in the Renmin Hospital of Wuhan University on February 5 or 6, 2020. Dynamic observations were conducted of independent risk factors found in retrospective studies from January 1 to January 31, 2020. The cellular immune status and blood CK were detected every three days. The date of disease on set was defined as the day when the cellular immune status was first detected(February 6, 2020). The blood CK, CD4 cell counts, and CD8 cell counts were obtained from electronic medical records.

\section{Statistics}


The frequency rate was used to describe the categorical variables, and the mean was used to describe the continuous variables. Differences between groups were tested using a chi-square test $t$-test or the MannWhitney $U$ test. Univariate, LASSO and multivariate Cox regression were used to screen for independent risk factors. The statistical analyses were performed using the GraphPad Prism8. The nomogram, calibration, receiver operating characteristic (ROC) curve, and no severe illness survival curve were established using $\mathrm{R}$ version 3.6.1. The risk score was calculated using the multivariate Cox regression was further used to calculate the cutoff value of independent risk factors based on the maximum Youden's index. A 2-sided a of less than 0.05 was considered to be statistically significant.

\section{Results}

\section{Presenting Characteristics}

All of the 317 cases in this study were confirmed as having SARS-CoV-2 infection. In total, $56.15 \%$ of the patients were female; however, gender differences were not statistically significant in the different groups(Table 1). The average age of 317 patients was 47.76 (SD 17.22). A total of $48(15.14 \%$ ) had a diagnosis of mild with a median age of $34(39.29 \pm 13.04), 116(36.59 \%)$ had a diagnosis of moderate with a median age of $34(38.78 \pm 12.32), 38(11.99 \%)$ had a diagnosis of severe with a median age of $56(58.24 \pm 15.12)$, and $115(36.28)$ had a diagnosis of critical with a median age of 59(56.89+17.09). The distribution of disease severity was completely different in the different ages. Patients younger than 40 years old were predominate among the mild and moderate cases. The majority of severe and critical patients were older than 50 (Table 1).

Among the 317 cases, fever was the most common symptom at onset of illness, which consisted of a population of $211(66.56 \%)$. Other common symptoms were dry cough(129[40.69\%]), fatigue(78[24.61\%]), expectoration(67[21.14\%]), and chest tightness(64[20.19\%]). Pharyngalgia, myalgia, diarrhea, and headache were less common symptoms at onset of illness(Table 1). A total of 29 patients $(9.15 \%)$ initially presented without any symptoms prior to laboratory findings and chest computed tomographic images. The incidences of fever and chest tightness were different in the different disease severities(Table 1).

\section{Laboratory Parameters}

Of the 317 patients, 175 of them had detail laboratory test results, including a blood routine, liver and kidney function, and immune function labs. As a patients' condition got worse, their lymphocyte count significantly decreased, while C-reactive protein(CRP), lacrate dehydrogenase(LDH), and creatine kinase(CK) also increased significantly(Table 2). More importantly, the CD3(count and ratio), CD4(count and ratio), CD8(count and ratio), and CD19(count and ratio) of severe or critical patients were lower than that of the mild or moderate patients(Table 2). In addition, the severe or critical patients had higher levels of IgG than the mild or moderate patients (Table 2).

\section{Screening for Independent Risk Factors and Constructing a Model for Predicting COVID-19 Progession}


The 175 patients were divided into two groups according to disease severity. Mild and moderate patients were included in the Mild Group(no severe illness), and severe and critical patients were included in the Severe Group. The no severe illness survival time was obtained from suspicious or confirmed diagnosis cases to the time when the patient became severe or to the time of discharge or January 31 . A total of 18 variables were considered to be risk factors using the univariate analysis(Cox regression) $(P<0.05)$ (Table S1).The LASSO Cox regression and the multivariate Cox regression were further used to screen six independent risk factors(Figure 1A, 1B, and Table S2). A nomogram base of the six independent risk factors was established to predict the no severe illness survival rates of 0.5-week, 1-week, 2-weeks, and 3weeks(Figure 1C). The c-index of this nomogram was $0.796(95 \% \mathrm{Cl}, 0.729-0.864)$. The calibration curves and the (area under the curve) AUC curve were used to verify the accuracy of this prediction model(Figure S1) which indicated that the predicted results are consistent with the actual results. The risk score was calculated using the multivariate Cox regression. The Severe Group had a higher risk score and lower no severe illness survival time and probability(Figure S2).

\section{Impact of Independent Risk Factors on no Severe Illness Survival Time}

The cutoff values of the six independent risk factors were calculated based on the risk score and the maximum Youden's index. The sensitivity and specificity of the six independent risk factors are indicated in Table S3. COVID-19 patients with ages over 50 years, a blood CK greater than 64U/L, a blood CD 4 cell count less than $461 \mathrm{per} / \mu \mathrm{L}$, or a blood CD 8 cell count less than $241 / \mu \mathrm{L}$ had a very high risk of progression to severe. These patients also had a lower no severe illness survival probability than other patients(Figure 2). The CD8\% and complement C3 were not included for AUC values lower than 7.0 or $p$-values greater than 0.05 .

\section{Comparison of the Predictive Value between CK, CD4, CD8 and MuLBSTA}

The MuLBSTA score is used to predict mortality in viral pneumonia. ${ }^{10,11}$ Six indexes are included in the MuLBSTA score system. These are age, hypertension, smoking history, multilobular infiltration, bacterial co-infection, and lymphopenia. ${ }^{10,11}$ The MuLBSTA score, CK, CD4, and CD8 were used to predict the risk of severe cases in this study. The AUC values of MuLBSTA, CK, CD4, and CD8 were $0.753,0.644,0.802$, and0.754, respectively. CD4-MuLBSTA(CD4 incorporated into MuLBSTA) had an AUC value of 0.833 , and CD4-CD8-MuLBSTA(CD4 and CD8 incorporated into MuLBSTA) had an AUC value of 0.828(Table S4).

After CK, CD4 or CD8 were incorporated into the MuLBSTA score, the net reclassification index(NRI) and integrated discrimination improvement(IDI) were used to compare the predictive value between the different models(Table S5). It was found that the predictive ability of CK was lower than the original MuLBSTA model. The predictive ability of CD4, CD8, and CK-MuLBSTA had no significant differences with the original MuLBSTA model. The predictive ability of CD4-MuLBSTA, CD8-MuLBSTA, and CD4-CD8MuLBSTA were better than the original MuLBSTA model $(\mathrm{P}<0.05)$. The predictive ability of the CD4-CD8MuLBSTA model was improved by $11.87 \%$ compared with the MuLBSTA model, which was improved compared to the other models(Table S5). 


\section{Dynamic Profile of CK, CD4 and CD8 in COVID-19 Patients}

To determine the significant clinical features of CK, CD4, and CD8 during COVID-19 progression, we tracked 25 mild or moderate patients hospitalized in February 5 and 6, 2020 in the Renmin Hospital of Wuhan University. From day 1 to day22, the dynamic changes in CK, CD4, and CD8 were recorded at threeday intervals. At the end of February 27, 2020, data from the two groups of patients with clinical courses were analyzed(Fig 3). Of the 25 patients, 4 patients progressed to severe or critical(Severe Group), and the remaining 21 patients had no progress, improved, or discharged(Mild Group). During hospitalization, the blood CK content in the Severe Group gradually increased. From the fifth laboratory test, the results began to show significant differences between the Severe Group and the Mild Group. The average CD4 cell count in the Severe Group began to decline significantly on the fourth day after onset of the disease. In the Severe Group, the CD8 cell count remained at a relatively low level after it dropped at day13. The CD4 and CD8 cell counts were relatively stable, but were at a high level in the Mild Group. The blood CK content in the Mild Group was relatively stable at a low level and fluctuated slightly near the cut-off point.

\section{Discussion}

In this report, the disease status of 317 patients was classified as mild, moderate, severe, and critical. The general clinical characteristics and laboratory parameters of the four types were investigated.

Furthermore, the independent risk factors for the progression of patients with COVID-19 were investigated using LASSO Cox and a multivariate Cox regression. In addition, a nomogram base of the six independent risk factors was established to predict the no severe illness survival rates of 0.5 -week, 1week, 2-weeks, and 3-weeks. The cut-off points of the most important four independent risk factors in COVID-19 progression were predicted based on the risks cores of 175 COVID-19 patients. Also, the dynamic relationship between three important independent risk factors(CK, CD4, and CD8) and disease changes in 25 COVID-19 patients were tracked to confirm the important role of these indicators in COVID19 progression.

Since the first case of unexplained pneumonia was first discovered in Wuhan city, ${ }^{12}$ the disease has spread rapidly, sweeping the world. COVID-19 was recognized by the WHO as an international emergency public health event. ${ }^{13}$ Current epidemiological studies have shown that the most common symptom of COVID-19 patients before and after consultation is fever. ${ }^{6,11,12,14}$ In this study, it was found that fever was identified in $66.56 \%$ of the 317 patients when they were hospitalized. A total of $48.26 \%$ of COVID-19 patients in this study were severe or critical, which is much higher than the severity reported by Wei jie et al.. ${ }^{14}$ The reason for this maybe due to insufficient hospital beds, and patients with more severe conditions were preferentially admitted. Although the fatality rate of SARS-CoV-2 appears to be lower than that of SARS-CoV and the Middle East Respiratory Syndrome Coronavirus(MERS-CoV), worse outcomes in SARS-CoV-2 patients once the disease enters the severe stage. A retrospective study showed a $61.5 \%$ mortality rate in severe COVID-19 patients. ${ }^{15}$ If patients having high risk factors to progress to 
severe or critical ill can be screened out early for early intervention, the proportion of severe or critically ill patients and mortality could be reduced significantly.

In this study, 175 patients with complete laboratory parameters were divided into a Mild Group(mild and moderate patients) and a Severe Group(severe and critical patients). A total of 33 variables were included in this study, including age and clinical laboratory parameters. Age, CK, CD4, CD8, CD8\%, and C3 were filtered out using LASSO and multivariate Cox regression, as they were considered to be independent risk factors that affect COVID-19 progression. CD8\% and C3 were not included in the following investigation for the $A U C<7.0$ or $p>0.05$. By predicting the no severe illness survival probability, it was found that COVID-19 patients with a blood CK of greater than $64 \mathrm{U} / \mathrm{L}$, a blood CD4 cell count less than 461 per/ $\mu \mathrm{L}$, or a blood CD8 cell count less than $241 \mathrm{per} / \mu \mathrm{L}$ had a very high risk of progression to severe. It has been reported that severe patients are typically seven years older than non-severe patients(median) based on a study of 1099 COVID-19 patients that indicated that older COVID-19 patients were more likely to progress to severe illness. ${ }^{14}$ Research has shown that T cells are reduced and eventually fail in COVID-19 patients. ${ }^{16}$ The results of this study are similar to the two findings mentioned above.

The MuLBSTA score includes six indicators and is used as an early warning of the fatality rate of viral pneumonia. ${ }^{10}$ An analysis of 99 cases of COVID-19 patients in Wuhan Jinyintan Hospital indicates that the MuLBSTA score can predict risk of death from COVID-19 patients. ${ }^{11}$ In this study, the independent prediction capabilities of CK, CD4, CD8, and MuLBSTA were analyzed, and the results verified that CD4 and CD8 had a higher AUC and sensitivity than CK and MuLBSTA for the early prediction of the incidence of severe illness. CK, CD4, and CD8 were then further incorporated into the MuLBSTA score model, and the prediction capabilities of various models were compared. It was found that the CD4-CD8-MuLBSTA model had the best prediction effect compared with the other models.

To confirm the important role of the selected independent risk factors in COVID-19 progression, we tracked the dynamic changes of $\mathrm{CK}, \mathrm{CD} 4$, and CD8 in 25 patients who were mild or moderate at the beginning of the experiment. After 21 days of observation, 4 of the 25 progressed to severe or critical, with CD4 and CD8 cell counts decreasing and the blood CK content increasing. Low levels of CD4 and CD8 induce poor immunity, and this maybe an important cause of critical illness or even death. In addition, increased CK maybe related to myocarditis and myocardial damage caused by the virus.

Until now, as no specific medicine or vaccine has been used for the treatment of coronavirus infections, ${ }^{17}$ it is necessary to predict independent risk factors for the early detection of potentially severe ill patients and to provide early intervention. Based on this research, a new predictive model was proposed. Early intervention and supportive treatment of patients whose age, CK, CD4, and CD8 values are in the dangerous range may have important significance in reducing the severity and mortality of the disease.

This study has some limitations. First, the basic clinical characteristics of this study came from 317 COVID-19 patients, and only 175 cases were included in the model construction to screen for independent risk factors. Only 25 patients were tracked to observe the CK, CD4, and CD8 values during disease 
progression. Other characteristics of these 25 patients should have been collected and analyzed. All of the data collected in this study were based on a single center with a small sample. Second, the conditions of patients still hospitalized may change in the next follow-up, and the final survival outcome could not be included. Third, some patients had severe underlying diseases before becoming infected with the virus, so there may be bias in the calculation of the no severe illness survival time.

\section{Conclusions}

COVID-19 quickly broke out and spread worldwide since it was first discovered in Wuhan. No specific medicine has been used for the treatment of coronavirus infections. It is necessary to establish a new predictive model that can be used to screen potential critical patients and provide early intervention. Age $>50, C K>64, C D 4 \leq 461$, and CD $8 \leq 241$ were predicted to be major independent risk factors that could promote COVID-19 progression. CD4 and CD8 were incorporated into the MuLBSTA to establish a new model, which is an ideal risk prediction model for COVID-19 patients.

\section{Abbreviations}

COVID-19: Coronavirus Disease 2019; CK: Creatine Kinase; SARS: Severe acute respiratory syndrome; MERS: Middle eastern respiratory syndrome; SARS-CoV-2: Severe Acute Respiratory Syndrome Coronavirus 2; NHCPRC: the National Health Commission of the People's Republic of China; ROC: Receiver operating characteristic; CRP: C-reactive protein; LDH: Lacrate dehydrogenase.

\section{Declarations}

Ethics approval and consent to participate: This study was approved by the Ethics Committee of the Renmin Hospital of Wuhan University(approval number: WDRY2020-K009), who waived the requirement for patients' informed consent referring to the CIOMS guideline.

Consent for publication: Not applicable

Availability of data and materials: The datasets used and/or analysed during the current study are available from the corresponding author on reasonable request.

Competing interests: We declare no competing interests.

Funding: This work was supported by award from the National Science Foundation of China Grants 81770095(to Q. Geng) and 81700093(to T. Fan). The sponsors had no role in this study design, data collection, analysis, or writing of the report.

Authors' contributions: T. Fan, Z. Lu, R. Xiong, X. Shen and Q. Geng collected data. T. Fan, B. Hao, B. Shen, S. Yang, Z. Huang and Q. Geng analyzed data. T. Fan, S. Yang and Q. Geng wrote the manuscript. T. Fan, 
B. Hao and Q. Geng contributed to the figures. W. Jiang, L. Zhang, D. Li, R. He, H. Meng, W. Lin, H. Feng and Q. Geng contributed to interpretation of data.

Acknowledgements: We thank all patients and their families involved in this study.

\section{References}

1. Li Q, Guan X, Wu P, et al. Early Transmission Dynamics in Wuhan, China, of Novel CoronavirusInfected Pneumonia. N Engl J Med 2020; published online Jan 29. DOIه1056/NEJMoa2001316

2. Bao Y, Sun Y, Meng S, et al. 2019-nCoV epidemic: address mental health care to empower society. Lancet 2020;395:e37-8.

3. Huang C, Wang Y, Li X, et al. Clinical features of patients infected with 2019 novel coronavirus in Wuhan, China. Lancet 2020;395:497-506.

4. Paules $\mathrm{Cl}$, Marston $\mathrm{HD}$, and Fauci AS. Coronavirus Infections-More Than Just the Common Cold. JAMA 2020; published online Jan 23. DOIه1001/jama.2020.0757.

5. Parry J. Wuhan: Britons to be evacuated as scientists estimate 44000 cases of $2019-n C O V$ in the city. BMJ 2020;368:m351.

6. Wang D, Hu B, Hu C, et al. Clinical Characteristics of 138 Hospitalized Patients With 2019 Novel Coronavirus-Infected Pneumonia in Wuhan, China. JAMA 2020; published online Feb 7. DOI区 1001/jama.2020.1585

7. Wu JT, Leung $\mathrm{K}$ and Leung GM. Nowcasting and forecasting the potential domestic and international spread of the 2019-nCoV outbreak originating in Wuhan, China: a modelling study. Lancet 2020;395:689-97.

8. Zhu N, Zhang D, Wang W, et al. A Novel Coronavirus from Patients with Pneumonia in China, 2019. N Engl J Med 2020; 382:727-33.

9. Clinical management of severe acute respiratory infection when novel coronavirus ( $\mathrm{nCoV}$ ) infection is suspected: interim guidance. Published January 28, 2020. Accessed January 31, 2020. https://apps.who.int/iris/handle/10665/330893.

10. Guo L, Wei D, Zhang X, et al. Clinical Features Predicting Mortality Risk in Patients With Viral Pneumonia: The MuLBSTA Score. Front Microbiol 2019;10:2752.

11. Chen N, Zhou M, Dong X, et al. Epidemiological and clinical characteristics of 99 cases of 2019 novel coronavirus pneumonia in Wuhan, China: a descriptive study. Lancet 2020;395:507-13.

12. Young BE, Ong SWX, Kalimuddin S, et al. Epidemiologic Features and Clinical Course of Patients Infected With SARS-CoV-2 in Singapore. JAMA 2020; published online Mar 3. DOIX 1001/jama.2020.3204

13. Coronavirus disease (COVID-19) outbreak https://www.who.int/emergencies/diseases/novelcoronavirus-2019 
14. Guan WJ, Ni ZY, Hu Y, et al. Clinical Characteristics of Coronavirus Disease 2019 in China. N Eng/ J Med2020; published online Feb 28. DOIه1056/NEJMoa2002032

15. Yang $X, Y u Y, X u$ J, et al. Clinical course and outcomes of critically ill patients with SARS-CoV-2 pneumonia in Wuhan, China: a single-centered, retrospective, observational study. Lancet Respir Med2020; published online Feb 24. DOIه1016/S2213-2600(20)30079-5

16. Ling Y, Xu SB, Lin YX, et al. Persistence and clearance of viral RNA in 2019 novel coronavirus disease rehabilitation patients. Chin Med J 2020; published online Feb 28. DOI区 1097/CM9.0000000000000774

17. de Wit E, van Doremalen N, Falzarano D, et al. SARS and MERS: recent insights into emerging coronaviruses. Nat Rev Microbiol 2016;14:523-34.

\section{Tables}


Table 1. Baseline Characteristics of Patients Infected With 2019-nCoV

\begin{tabular}{|c|c|c|c|c|c|c|}
\hline \multirow[t]{2}{*}{ Variable } & \multirow{2}{*}{$\begin{array}{c}\text { Total } \\
\text { (No. \%) }\end{array}$} & \multicolumn{4}{|c|}{ Disease Severity } & \multirow[t]{2}{*}{ P Value } \\
\hline & & $\begin{array}{c}\text { Mild } \\
\text { (No. \%) }\end{array}$ & $\begin{array}{c}\text { Moderate } \\
\text { (No. \%) }\end{array}$ & $\begin{array}{l}\text { Severe } \\
\text { (No. \%) }\end{array}$ & $\begin{array}{l}\text { Critical } \\
\text { (No. \%) }\end{array}$ & \\
\hline \multicolumn{7}{|l|}{ Sex } \\
\hline Female & $178(56.15)$ & $26(8.2)$ & $70(22.08)$ & $26(8.2)$ & $56(17.67)$ & 0.12 \\
\hline Male & 139(43.85) & $22(6.94)$ & $46(14.51)$ & $12(3.79)$ & $59(18.61)$ & \\
\hline \multicolumn{7}{|l|}{ Age } \\
\hline$<=30$ & $57(17.98)$ & $15(4.73)$ & $38(11.99)$ & $1(0.32)$ & $3(0.95)$ & $<0.001$ \\
\hline $31-40$ & $68(21.45)$ & $16(5.05)$ & 38(11.99) & $5(1.58)$ & $9(2.84)$ & \\
\hline $41-50$ & $43(13.56)$ & $6(1.89)$ & $17(5.36)$ & $6(1.89)$ & $14(4.42)$ & \\
\hline $51-60$ & $53(16.72 \square$ & $6(1.89)$ & $14(4.42)$ & $9(2.84)$ & $24(7.57)$ & \\
\hline$>60$ & $96 \square 30.28 \square$ & $5(1.58)$ & $9(2.84)$ & $17(5.36)$ & $65(20.5)$ & \\
\hline \multicolumn{7}{|l|}{ Fever } \\
\hline Yes & $211 \llbracket 66.56 \square$ & $25(7.89)$ & $70(22.08)$ & $26(8.2)$ & $90(28.39)$ & 0.003 \\
\hline No & $106 \square 33.44 \square$ & $23(7.26)$ & $46(14.51)$ & $12(3.79)$ & $25(7.89)$ & \\
\hline \multicolumn{7}{|l|}{ Dry cough } \\
\hline Yes & $129 \square 40.69 \square$ & $13(4.1)$ & $49(15.46)$ & $19(5.99)$ & $48(15.14)$ & 0.16 \\
\hline No & $188 \square 59.31 \square$ & $35(11.04)$ & $67(21.14)$ & 19(5.99) & $67(21.14)$ & \\
\hline \multicolumn{7}{|l|}{ Expectoration } \\
\hline Yes & 67ロ21.14ロ & $10(3.15)$ & $20(6.31)$ & $4(1.26)$ & $33(10.41)$ & 0.06 \\
\hline No & $250 \square 78.86 \square$ & 38(11.99) & $96(30.28)$ & $34(10.73)$ & $82(25.87)$ & \\
\hline \multicolumn{7}{|l|}{ Pharyngalgia } \\
\hline Yes & $42 \square 13.25 \square$ & $9(2.84)$ & $18(5.68)$ & $3(0.95)$ & $12(3.79)$ & 0.25 \\
\hline No & $275 \square 86.75 \square$ & 38(11.99) & $96(30.28)$ & 38(11.99) & 103(32.49) & \\
\hline \multicolumn{7}{|l|}{ Chest tightness } \\
\hline Yes & $64 \llbracket 20.19 \square$ & $8(2.52)$ & $13(4.1)$ & $12(3.79)$ & $31(9.78)$ & 0.006 \\
\hline No & $253 \square 79.81 \square$ & $40(12.62)$ & 103(32.49) & $26(8.2)$ & $84(26.5)$ & \\
\hline \multicolumn{7}{|l|}{ Myalgia } \\
\hline Yes & 37ロ11.67ロ & $8(2.52)$ & $12(3.79)$ & $3(0.95)$ & $14(4.42)$ & 0.59 \\
\hline No & $380 \square 119.87 \square$ & $40(12.62)$ & $104(32.81)$ & $35(11.04)$ & 101(31.86) & \\
\hline \multicolumn{7}{|l|}{ Fatigue } \\
\hline Yes & $78 \square 24.61 \square$ & $11(3.47)$ & $36(11.36)$ & $5(1.58)$ & $26(8.2)$ & 0.13 \\
\hline No & $239 \llbracket 75.39 \square$ & $37(11.67)$ & $80(25.24)$ & $33(10.41)$ & $89(28.08)$ & \\
\hline \multicolumn{7}{|l|}{ Diarrhea } \\
\hline Yes & $23 \square 7.26 \square$ & $3(0.95)$ & $8(2.52)$ & $1(0.32)$ & $11(3.47)$ & 0.53 \\
\hline No & 294(92.74) & $45(14.2)$ & 108(34.07) & 37(11.67) & 104(32.81) & \\
\hline \multicolumn{7}{|l|}{ Headache } \\
\hline Yes & $22(6.94)$ & $5(1.58)$ & $10(3.15)$ & $0(0.00)$ & $7(2.21)$ & 0.22 \\
\hline No & 295(93.06) & $43(13.56)$ & $106(33.44)$ & $38(11.99)$ & 108(34.07) & \\
\hline
\end{tabular}


Table 2. Laboratory Findings of Patients Infected With 2019-nCoV on Admission to Hospital

\begin{tabular}{|c|c|c|c|c|c|c|}
\hline \multirow[t]{2}{*}{ Variable } & \multirow{2}{*}{$\begin{array}{l}\text { Normal } \\
\text { Range }\end{array}$} & \multicolumn{4}{|c|}{ Disease Severity } & \multirow[t]{2}{*}{ P Value } \\
\hline & & $\begin{array}{c}\text { Mild } \\
\text { Mean } \\
(95 \% \mathrm{CI})\end{array}$ & $\begin{array}{c}\text { Moderate } \\
\text { Mean } \\
(95 \% \mathrm{CI})\end{array}$ & $\begin{array}{c}\text { Severe } \\
\text { Mean } \\
(95 \% \mathrm{CI})\end{array}$ & $\begin{array}{c}\text { Critical } \\
\text { Mean } \\
(95 \% \mathrm{CI})\end{array}$ & \\
\hline $\begin{array}{l}\text { White blood } \\
\text { cell count, } \times 109 / \mathrm{L}\end{array}$ & 5 & $\begin{array}{c}5.16 \\
(4.47 \text { to } 5.86)\end{array}$ & $\begin{array}{c}4.73 \\
\text { (4.39 to } 5.07)\end{array}$ & $\begin{array}{c}5.37 \\
\text { (4.1 to } 6.64)\end{array}$ & $\begin{array}{c}5.22 \\
(4.69 \text { to } 5.75)\end{array}$ & 0.35 \\
\hline $\begin{array}{l}\text { Neutrophil } \\
\text { count, } \times 109 / \mathrm{L}\end{array}$ & $1.8-6.3$ & $\begin{array}{c}2.98 \\
(2.35 \text { to } 3.61)\end{array}$ & $\begin{array}{c}2.62 \\
\text { (2.38 to } 2.87)\end{array}$ & $\begin{array}{c}3.95 \\
(2.64 \text { to } 5.26)\end{array}$ & $\begin{array}{c}3.83 \\
\text { (3.31 to } 4.35)\end{array}$ & $<0.001$ \\
\hline $\begin{array}{l}\text { Lymphocyte } \\
\text { count, } \times 109 / \mathrm{L}\end{array}$ & $1.1-3.2$ & $\begin{array}{c}1.55 \\
(1.33 \text { to } 1.77)\end{array}$ & $\begin{array}{c}1.58 \\
(1.41 \text { to } 1.74)\end{array}$ & $\begin{array}{c}1.02 \\
(0.78 \text { to } 1.26)\end{array}$ & $\begin{array}{c}0.96 \\
(0.82 \text { to } 1.09)\end{array}$ & $<0.001$ \\
\hline $\begin{array}{l}\text { Platelet } \\
\text { count, } \times 109 / \mathrm{L}\end{array}$ & \multicolumn{6}{|c|}{ (182.7 to 235.7) (194.4 to 221.7) (169.9 to 253.9) (171.0 to 202.7) } \\
\hline $\begin{array}{l}\text { C-reactive protein, } \\
\mathrm{mg} / \mathrm{L}\end{array}$ & $0-5$ & $\begin{array}{c}4.99 \\
(1.02 \text { to } 8.95)\end{array}$ & $\begin{array}{c}9.21 \\
\text { (5.87 to } 12.55)\end{array}$ & $\begin{array}{c}31.1 \\
(13.98 \text { to } 48\end{array}$ & $\begin{array}{c}43.24 \\
2.70 \text { to } 53.77)\end{array}$ & $<0.001$ \\
\hline $\begin{array}{l}\text { Alanine } \\
\text { aminotransferase, U/L }\end{array}$ & \multicolumn{5}{|c|}{ (15.78 to 34.07 ) (17.26 to 27.05 ) (20.58 to 38.75$)$ (23.13 to 34.15$)$} & 0.28 \\
\hline $\begin{array}{l}\text { Aspartate } \\
\text { aminotransferase, U/L }\end{array}$ & $15-40$ & \multicolumn{5}{|c|}{ (20.06 to 29.64 ) (20.40 to 25.30 ) (22.93 to 36.29 ) (28.66 to 37.82 ) } \\
\hline Urea, & 3.1-8.0 & $\begin{array}{c}3.71 \\
\text { (3.11 to } 4.3)\end{array}$ & $\begin{array}{c}4.05 \\
\text { (3.79 to } 4.3)\end{array}$ & $\begin{array}{c}6.17 \\
\text { (4.6 to } 7.74)\end{array}$ & $\begin{array}{c}5.74 \\
(4.36 \text { to } 7.12)\end{array}$ & 0.003 \\
\hline Cre & 7-97 & \multicolumn{5}{|c|}{ (46.13 to 58.68$)$ (51.71 to 57.18 ) (54.75 to 81.36 ) (50.26 to 138.0$)$} \\
\hline $\begin{array}{l}\text { Lactate } \\
\text { dehydrogenase, U/L }\end{array}$ & $120-250$ & \multicolumn{5}{|c|}{ (165.1 to 207.2) (182.4 to 205.2) (201.1 to 283.0) (262.7 to 325.5) } \\
\hline $\mathrm{U} / \mathrm{L}$ & -310 & \multicolumn{5}{|c|}{ (24.26 to 105.7 ) (58.94 to 83.11$)$ (45.81 to 129.5 ) (83.10 to 163.7$)$} \\
\hline & -86 & \multicolumn{5}{|c|}{ (68.45 to 75.84 ) (68.62 to 72.99$)$ (61.38 to 73.99 ) (54.36 to 62.03 ) } \\
\hline $\mathrm{CD}^{3}$ & $723-2737$ & $\begin{array}{c}1124 \\
\text { (923.0 to } 132\end{array}$ & $\begin{array}{c}1036 \\
33.0 \text { to } 114\end{array}$ & $\begin{array}{c}658.4 \\
5.9 \text { to } 851\end{array}$ & $\begin{array}{c}577.1 \\
60.1 \text { to } 694\end{array}$ & $<0.001$ \\
\hline $\mathrm{CD} 4(\%)$ & $33-58$ & $\begin{array}{c}41.71 \\
\text { (38.81 to } 44.61)\end{array}$ & $\begin{array}{c}41.19 \\
(39.18 \text { to } 43.20)\end{array}$ & $\begin{array}{c}41.85 \\
(37.44 \text { to } 46.26)\end{array}$ & $\begin{array}{c}31.91 \\
(29.23 \text { to } 34.60)\end{array}$ & $<0.001$ \\
\hline CD4 cour & 1612 & \multicolumn{5}{|c|}{ (573.6 to 766.3 ) (544.8 to 676.7) (288.5 to 517.0) (247.2 to 382.7) } \\
\hline CD8(\%) & $13-39$ & \multicolumn{5}{|c|}{ (24.62 to 29.51 ) (24.41 to 27.08 ) (18.63 to 26.64$)$ (20.97 to 26.98$)$} \\
\hline CD8 & $0-1129$ & \multicolumn{5}{|c|}{ (355.1 to 533.5 ) (328.7 to 410.8 ) (151.7 to 303.4 ) (183.9 to 291.9) } \\
\hline CD4 & ratio $0.9-2.0$ & $\begin{array}{c}1.64 \\
(1.43 \text { to } 1.85)\end{array}$ & $\begin{array}{c}1.93 \\
(1.46 \text { to } 2.4)\end{array}$ & $\begin{array}{c}2.55 \\
(1.28 \text { to } 3.81)\end{array}$ & $\begin{array}{c}1.63 \\
\text { (1.38 to } 1.87)\end{array}$ & 0.17 \\
\hline CD1 & $5-22$ & \multicolumn{5}{|c|}{ (11.53 to 16.55$)$ (12.00 to 14.43$)$ (15.30 to 28.34$)$ (13.39 to 17.54$)$} \\
\hline CD19 & 6 & \multicolumn{5}{|c|}{ (169.4 to 250.5 ) (163.0 to 231.2 ) (120.0 to 236.4 ) (108.4 to 149.6$)$} \\
\hline CD16+56 (\%) & $\angle 0$ & \multicolumn{5}{|c|}{ (3.458 to 31.86) (11.22 to 14.97 ) (6.227 to 11.61 ) (20.21 to 27.49$)$} \\
\hline CD16+56 count, / $\mu \mathrm{L}$ & 24 & \multicolumn{5}{|c|}{ (82.20 to 240.3 ) (150.4 to 216.5 ) (55.13 to 110.4 ) (154.7 to 225.3 ) } \\
\hline IgG, g/L & 16 & \multicolumn{5}{|c|}{ (10.32 to 13.34$)$ (11.01 to 12.62 ) (15.44 to 20.73 ) (12.64 to 14.93$)$} \\
\hline $\operatorname{IgM}, g / L$ & 0.4-3.45 & $\begin{array}{c}1.19 \\
(1.03 \text { to } 1.35)\end{array}$ & $\begin{array}{c}1.2 \\
(1.07 \text { to } 1.33)\end{array}$ & $\begin{array}{c}1.08 \\
(0.74 \text { to } 1.41)\end{array}$ & $\begin{array}{c}1.13 \\
\text { (1.0 to } 1.27)\end{array}$ & 0.79 \\
\hline $\operatorname{IgA}, \mathrm{g} / \mathrm{L}$ & $0.76-3.9$ & $\begin{array}{c}1.9 \\
(1.55 \text { to } 2.25)\end{array}$ & $\begin{array}{c}4.49 \\
(-0.42-9.39)\end{array}$ & $\begin{array}{c}1.83 \\
(1.44 \text { to } 2.22)\end{array}$ & $\begin{array}{c}2.23 \\
\text { (1.94 to } 2.52)\end{array}$ & 0.71 \\
\hline $\mathrm{gE}, \mathrm{IU} / \mathrm{mL}$ & $<100$ & 71.7 & 88.89 & 59.83 & 84.1 & 0.89 \\
\hline
\end{tabular}




\begin{tabular}{lcccccc}
\hline Complement C3, g/L & $0.81-1.6$ & 0.78 & 0.83 & 0.89 & 0.88 & 0.09 \\
& & $(0.72$ to 0.84$)$ & $(0.79$ to 0.87$)$ & $(0.81$ to 0.98$)$ & $(0.82$ to 0.94$)$ & 0.003 \\
Complement C4, g/L & \multirow{2}{*}{$0.1-0.4$} & 0.2 & 0.24 & 0.22 & 0.28 & 0.003 \\
& & $(0.17$ to 0.23$)$ & $(0.22$ to 0.27$)$ & $(0.19$ to 0.25$)$ & $(0.25$ to 0.31$)$ & \\
\hline
\end{tabular}

\section{Figures}
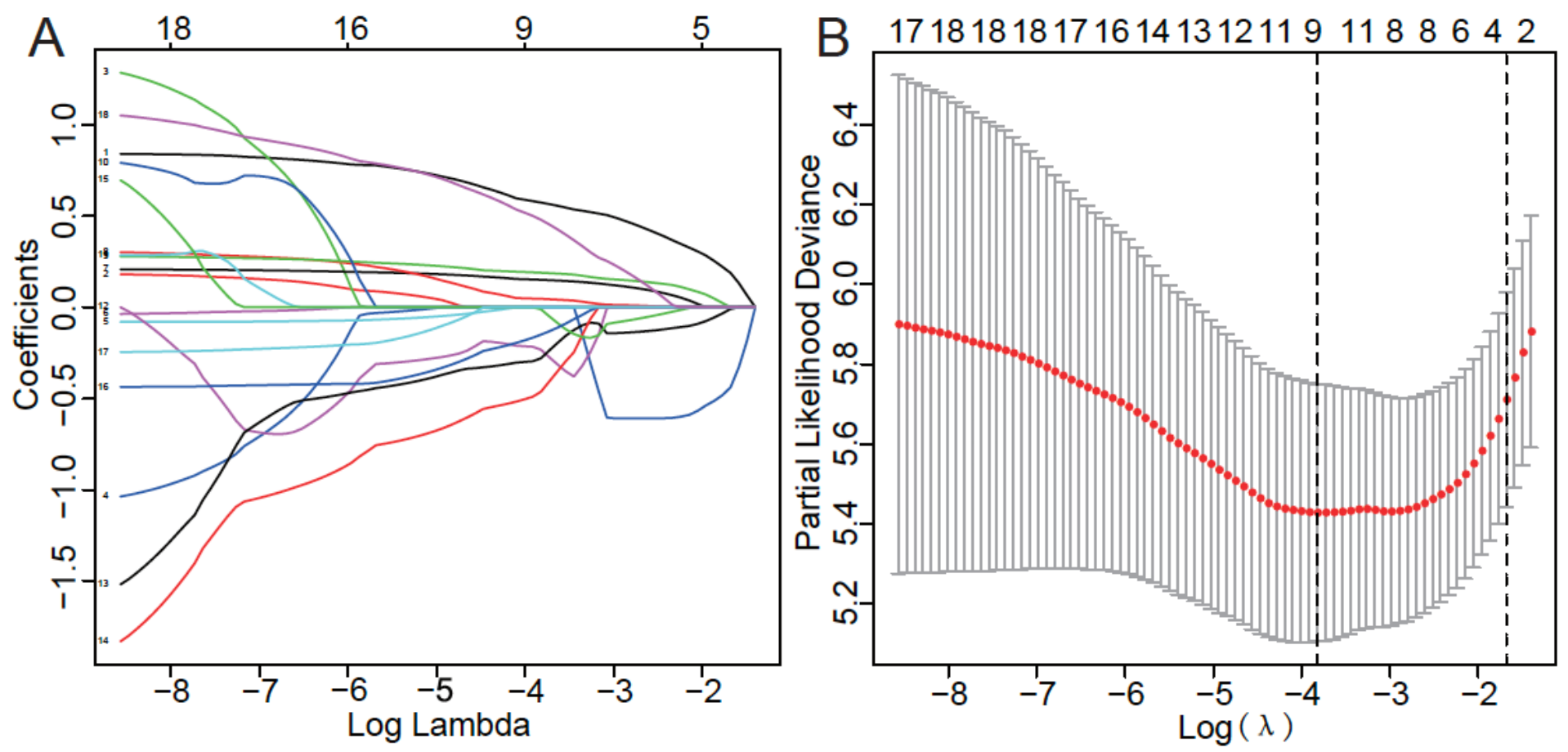

C Points

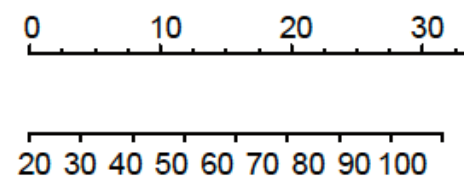

Age

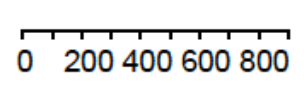

CD4

CD8\%

CD8

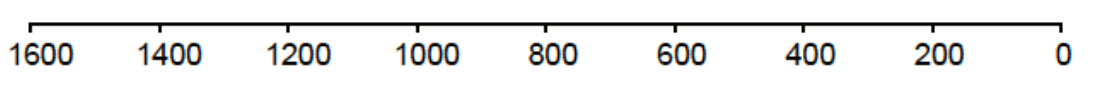

C3

\begin{tabular}{lllllllllllllllll}
\hline 65 & 60 & 55 & 50 & 45 & 40 & 35 & 30 & 25 & 20 & 15 & 10 & 5 & 0 & & & \\
\hline 0 & 100 & 200 & 300 & 400 & 500 & 600 & 700 & 800 & 900 & 1000 & 1100 & 1200 & 1300
\end{tabular}

Total Points 0.10 .30 .50 .70 .91 .11 .31 .5

Total Points

\begin{tabular}{cccccccccc}
\hline 0 & 40 & 60 & 80 & 100 & 120 & 140 & 160 & 180 & 200 \\
illness survival & & & & & & & & 0.9 & 0.80 .7
\end{tabular}

1-week no severe illness survival $0 . 9 \longdiv { 0 . 8 0 . 7 0 . 6 0 . 5 0 . 4 0 . 3 }$

2-week no severe illness survival

3-week no severe illness survival 
Figure 1

Selected risk factors that predict the no severe illness survival. (A) The log(Lambda) values of 18 parameters as shown using the LASSO coefficient profiles. (B) The most proper $\log (\lambda)$ value in the LASSO Cox regression. (C) Establishment of the nomogram that was based on the six independent risk factors resulting from the multivariate Cox regression to predict the 0.5-week, 1-week, 2-weeks, and 3-weeks no severe illness survival for COVID-19 patients in the developing set.
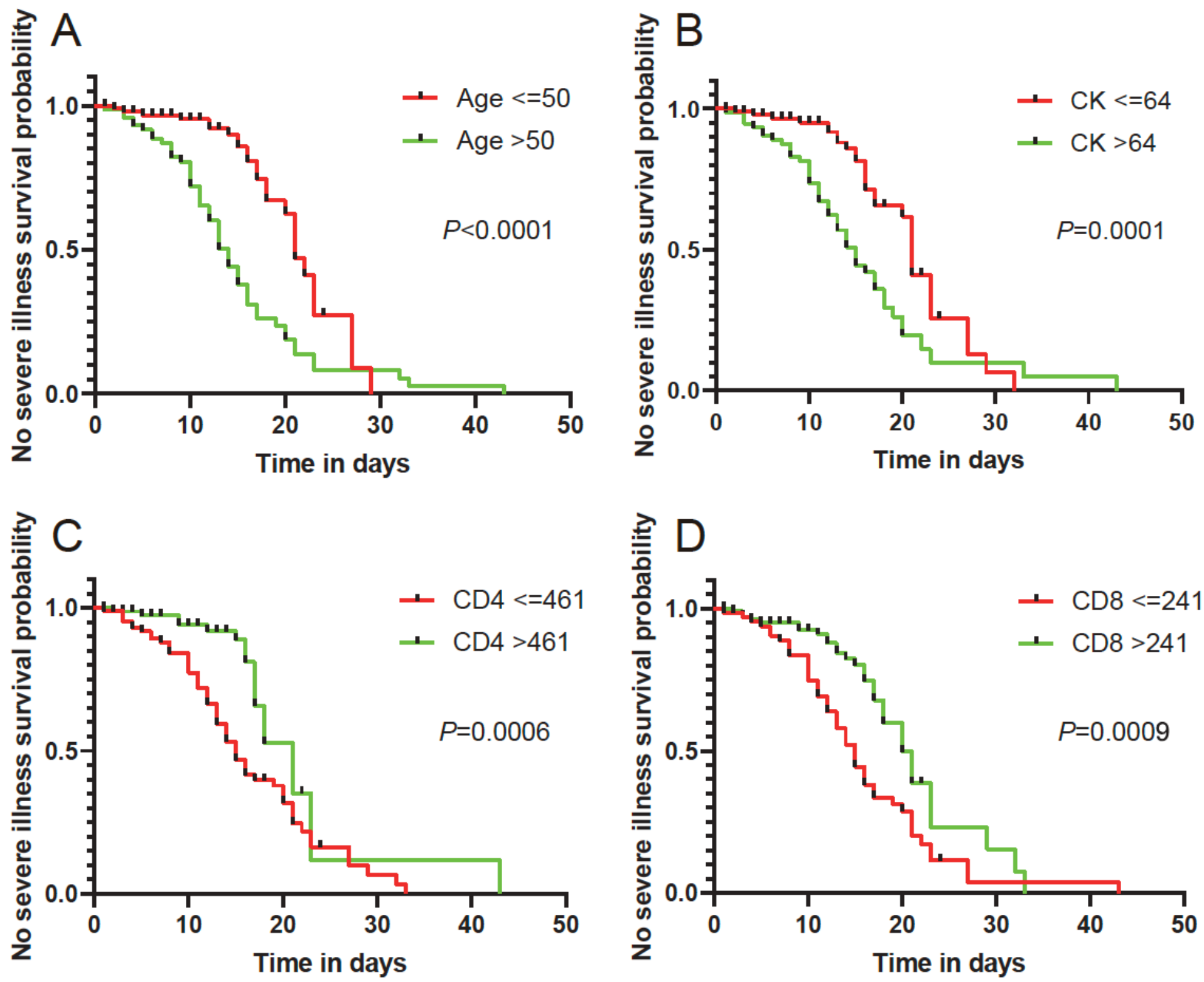

Figure 2

Evaluating the predictive efficiencies of independent risk factors for the no severe illness survival. The Kaplan-Meier survival curves in (A), (B), (C), and (D) show that COVID-19 patients with age $>50, C K>64$, CD4 $\leq 461$, or $C D 8 \leq 241$ has a poorer outcome than COVID-19 patients with age $\leq 50, C K \leq 64, C D 4>461$, or CD8>241. 

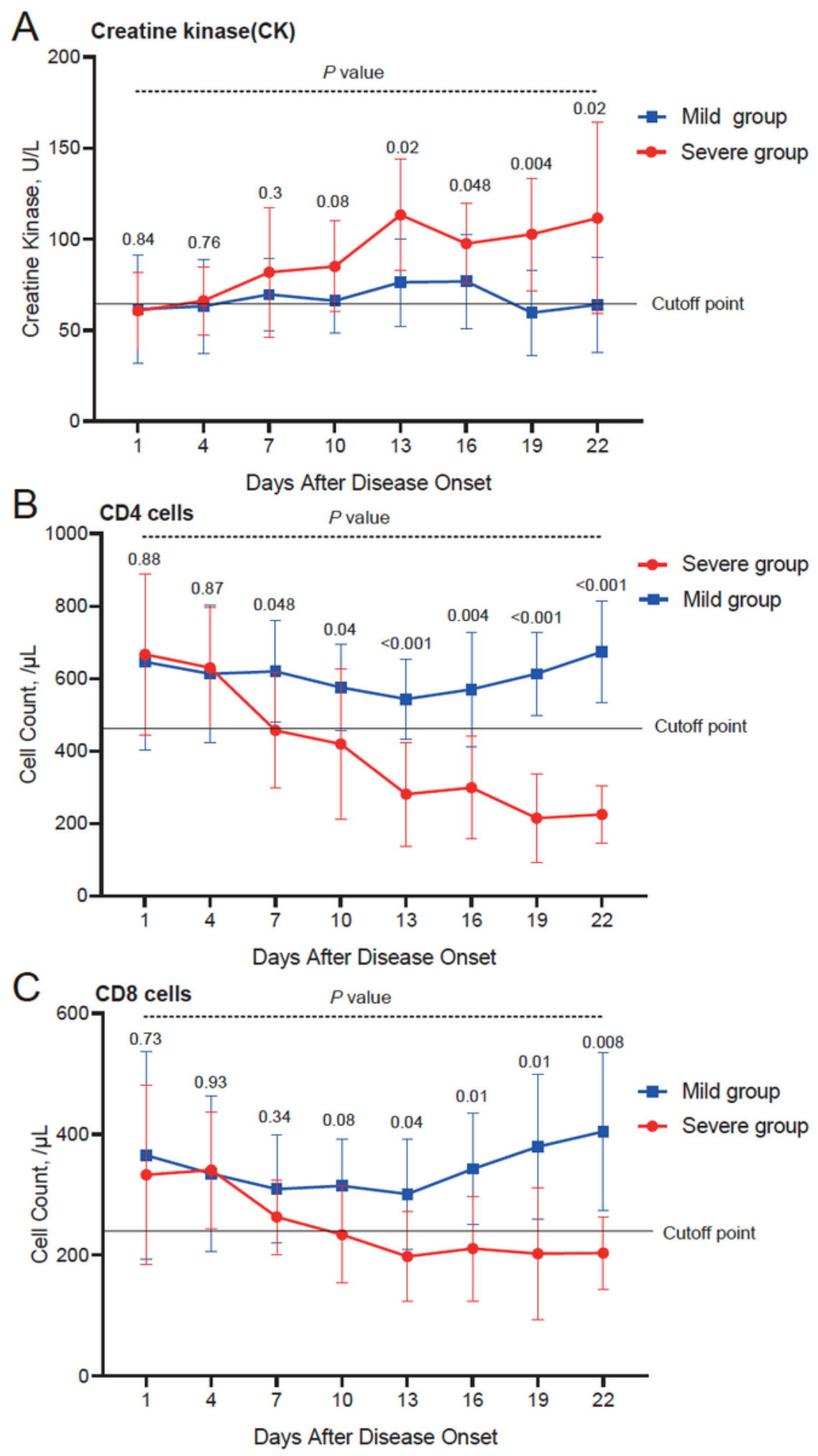

\section{Figure 3}

Dynamic profile of major independent risk factors in 25 patients with COVID-19. (A) The blood CK content dynamic curve in the Severe Group and the Mild Group. (B) The blood CD4 cell count in the Severe Group and the Mild Group. (C) The blood CD8 cell count in the Severe Group and the Mild Group.

\section{Supplementary Files}


This is a list of supplementary files associated with this preprint. Click to download.

- Additionalfile1.doc 